\title{
DESKRIPTIF KUALITATIF BISNIS DUPLIKAT KUNCI ASGAR DI KECAMATAN PAMULANG - KOTA TANGERANG SELATAN
}

\author{
AMIN K. ELFACHMI ${ }^{1)}$, ABDUL ROZAK ${ }^{2)}$ \\ ${ }^{1,}$ Dosen Program Studi Pendidikan Ekonomi Universitas Pamulang \\ ${ }^{2}$ Mahasiswa Program Studi Pendidikan Ekonomi Universitas Pamulang \\ *)email: ${ }^{1)}$ dosen00735@unpam.ac.id
}

\begin{abstract}
ABSTRAK
Usaha duplikat kunci ASGAR adalah salah satu usaha yang bergerak di bidang jasa, yang beralamat di bunderan pamulang Jl. Siliwangi No. 2, Pamulang, Kec. Pamulang Barat - Kota Tangerang Selatan.

Pengelolaan Sumber Daya Manusiannya bapak Ade sangat sederhana contohnya dalam rekrumen karyawannya bapak Ade hanya mengajak anaknya sebagai karyawannya, anak yang peratama namanya Rozak, Rozak sebagai karyawan produksi dan yang kedua namanya Rizal, Rizal sebagai karyawan keuangan

Pengelolaan Operasionalnya usaha duplikat kunci ASGAR, setiap hari bapak Ade buka dari jam 08:00-21:00 WIB,

Pengelolaan pemasarannya : Produk yang ditawarkan Usaha Duplikat Kunci yaitu berupa jasa yang menyediakan layanan duplikat kunci dan servis kunci. Harga (Price), Harga yang ditetapkan oleh duplikat kunci ASGAR berda-beda tergantung kuncinya misalkan kunci rumah harga duplikatnya Rp.12.000 - Rp.15.000 sedangkan harga kunci motor dan mobil Rp.25.000 - Rp.50.000, kemudin harga servis itu tergantung tingkat servisnya sehingga harganya tidak tetap. Distribusi (Place) perusahaan menempatkan usahanya supaya mudah dijangkau oleh konsumen yaitu dengan menempatkannya dekat dengan jalan raya dan dekat kampus universitas pamulang (UNPAM). Promosi (Promotion) Bentuk promosi yang dilakukan oleh usaha duplikat kunci ASGAR selama ini masih promosi dari mulut ke mulut serta testimonial dari konsumen yang telah menggunakan jasa Duplikat Kunci ASGAR Orang (People) merupakan unsur penting dalam pemasaran.Setiap organisasi jasa harus jelas menentukan apa yang diharapkan dari setiap karyawan dalam dengan pelanggan. Bukti fisik (Physical Evidence) bersifat sebuah produk yang berbentuk barang dan Jasa duplikat kunci lebih mengarah kepada kualitas dan kuantitas. Proses (Process) yaitu bagaimana caranya membuat proses produksi berupa jasa yang dapat diterima oleh konsumen duplikat kunci ASGAR

Pesaing dan Persaingan banyaknya usaha-usaha duplikat kunci dan kunci otomatis yang tidak bisa di duplikat sekarang dapat menjadi ancaman bagi kelanjutan usaha duplikat kunci di masa depan.
\end{abstract}

Kata Kunci: Bisnis, SWOT, Duplikat Kunci 


\section{PENDAHULUAN}

\section{A. Konteks Penelitian}

Pembangunan ekonomi di Indonesia UKM selalu digambarkan sebagai sektor yang mempunyai peranan yang penting, karena sebagian besar jumlah penduduknya berpendidikan rendah dan hidup dalam kegiatan usaha kecil baik di sektor tradisional maupun modern. Usaha jasa merupakan jenis usaha yang memiliki aspek dan lingkup bisnis yang paling luas dibandingkan dengan jenis usaha lainnya. Selain memiliki keanekaragaman produk dan pelayanan, jenis usaha jasa termasuk memiliki persaingan yang paling ketat. Strategi pengelolaan usaha dituntut untuk senantiasa mampu menyerap perubahan pasar dan selera konsumen yang selalu berubah setiap saat. Salah satunya adalah strategi yang berfokus pada konsumen (consumer orrientation) yang tujuannya untuk memaksimalkan kepuasan konsumen dengan memahami keinginan pelanggan seperti perilaku, kebutuhan, dan keinginan

Usaha pembuatan duplikat kunci ASGAR sudah berdiri sejak tahun 2000 di Kecamatan Pamulang - kota Tangerang Selatan, usaha duplikat kunci ini di kelolah oleh bapak Ade
Suryana secara baik dan teliti, sehingga ada peningkatannya dari tahun-ketahun. Dalam perkembangannya selama delapanbelas tahun ini usaha pembuatan duplikat kunci sudah mulai menunjukan keberhasilannya, yang semula pembuatannya secara manual/ pake tangan menjadi modern pembuatannya dengan menggunakan mesin duplikat.

Pada jenis usaha jasa ini tentunya sasaran utama strategi dalam meningkatkan kualitas layanan adalah loyalitas konsumen. Sikap loyal konsumen ini dibentuk berdasarkan pada kepuasan konsumen, yaitu dengan memberikan penilaian konsumen terhadap produk yang dikonsumsinya atau yang dipakainya.

Berdasarkan latar belakang tersebut penulis tertarik untuk meneliti masalah ini dalam penulisan tugas akhir atau skripsi yang berjudul : "Deskriptif Kualitatif Bisnis Duplikat Kunci Asgar di Kecamatan Pamulang - Kota Tangerang Selatan".

\section{B. Fokus Penelitian}

1. Bagaimana gambaran pengelolaan usaha duplikat kunci ASGAR saat ini ? dalam penelitian ini pengelolaan yang dilakukan fokus 
kepada manajemen SDM, manajemen Operasional, dan manajemen Pemasaran.

2. Bagaimana analisis SWOT usaha jasa duplikat kunci ASGAR ?

\section{KAJIAN TEORI}

\section{A. Landasan Teori}

\section{Pengertian Manajemen}

Menurut Stoner dalam ( Handoko 1995 ), Manajemen adalah proses perencanaan, pengorganisasian, pengarahan, dan pengawasan usaha para anggota organisasi dan penggunaan sumber daya organisasi lainnya agar mencapai tujuan organisasi yang telah di tetapkan.

\section{Pengertin Bisnis}

bisnis adalah suatu organisasi yang menjual barang atau jasa kepada konsumen untuk

mendapatkan laba. Secara historis kata bisnis dari bahasa inggris (business), dari kata dasar busy yang berarti "sibuk" dalam konteks individu, komunitas, ataupun masyarakat. Dalam artian, sibuk mengerjakan aktivitas dan pekerjaan yang mendatangkan keuntungan.

\section{METODE PENELITIAN}

\section{A. Pendekatan dan Jenis Penelitian}

Pendekatan yang digunakan dalam penelitian ini adalah pendekatan kualitatif. Menurut Bogdan dan Taylor dalam Moleong

(2014:4) mendefinisikan metodologi kualitatif sebagai prosedur penelitian yang menghasilkan data deskriptif berupa kata-kata tertulis atau lisan dari orangorang dan perilaku yang dapat diamati.

\section{B. Lokasi Penelitian}

Lokasi penelitian adalah objek dimana penelitian ini dilakukan. Penelitian ini dilakukan di desa Pamulang, kecamatan Pamulang Barat kabupaten Banten. Alasan mengapa peneliti memilih wilayah Pamulang sebagai lokasi penelitian karena memudahkan peneliti dalam melakukan penelitian.

Cara peneliti memasuki lokasi penelitian tersebut yaitu dilakukan dengan mendatangi pemilik Usaha Duplikat Kunci di wilayah Pamulang, melakukan wawancara dan observasi dibeberapa tempat Usaha Duplikat Kunci di wilayah Pamulang. 


\section{Analisis Data}

1. Pengumpulan data

2. Reduksi data

3. Display data

4. Kesimpulan/verifikasi

\section{Pengecekan Keabsahan Temuan}

Salah satu syarat mutlak dalam penelitian adalah validitas dan reliabilitas yang optimal. Tujuan dari validitas dan reliabilitas itu sendiri adalah untuk mengoptimalkan rigor penelitian. Rigor merupakan tingkat atau derajat dimana hasil temuan dalam penelitian kualitatif bersifat autentik dan memiliki interpretasi yang dapat dipertanggungjawabkan. Validitas, reliabilitas, dan objektifitas dalam penelitian kualitatif dikenal dengan istilah kredibilitas, transferabilitas, dan konfirmabilitas.

1. Uji kredibilitas data

2. Uji Transferabilitas data

3. Uji depenabilitas data

4. Uji Komfirmabilitas data

PAPARAN DATA, HASIL TEMUAN PENELITIAN DAN PEMBAHASAN Deskripsi Usaha Bisnis Duplikat

\section{Kunci}

Usaha duplikat kunci ASGAR adalah salah satu usaha yang bergerak di bidang jasa, dan nama ASGAR tersebut adalah singkatan dari asli Garut karena pemilik usahanya asli orang Garut. Dimana usahat tersebut melayani pembuatan duplikat kunci apa pun, dari kunci motor, mobil, rumah, lemari, dan kunci berangkas pun bisa di duplikatkan.

Usaha tersebut didrikan pada tahun 1999 oleh bapak Anang, bapak Anang ini adalah orang pertama yang buka usaha duplikat kunci sebelum di teruskan oleh bapak Ade, Ade adalah saudara dari bapak anang, sebelum menjadi usaha duplikat kunci Ade seorang pedagang serabutan, pedagang serabutan itu adalah daganga apa aja. dalam pembuatan duplikat kunci bapak anang masih menggunakan tangannya secara manual dengan menggunakan kikir. kadang dalam pembuatannya bapak Ade pun membantunya sambil belajar, selama satu tahun bapak Anang memutuskan untuk berhenti karena pada waktu itu usaha duplikat kunci masih belum banyak peminatnya karena orang-orang lebih memilih instan dengan beli baru lagi. 


\section{Deskripsi Pengelolaan Usaha Bisnis}

\section{Duplikat Kunci ASGAR}

\section{a. Pengelolaan Sumberdaya Manusia (SDM)}

Sumber Daya Manusia (SDM) sangat perperan penting untuk mengatur pengelolaan SDM dan sumberdaya perusahaan agar memberikan hasil maksimal dan memiliki loyalitas tinggi. Selain itu juga akan memiliki profesionalitas terbaik yang dapat diandalkan untuk mencapai tujuan dan sasaran perusahaan.

Setiap pengelolaan Sumber Daya Manusia harus menciptakan SDM yang handal dan melakukan training, coaching dan motivation pada setiap karyawan agar mampu menjalankan tugas sebagaimana mestinya. Kemampuan inilah yang akan menjadi salah satu kunci kemajuan dan keberhasilan dari sebuah perusahaan. Bahkan daya saing tinggi akan membuat karyawan siap dengan tantangan arus globalisasi dan membuat perusahan mampu memanfaatkan peluang sebaik baiknya.

\section{b. Pengelolaan Operasional}

Pengelolaan Operasional menurut T. Hani Handoko (2003:3) proses perencanaan, pengorganisasian, pengarahan, dan pengawasan usahausaha para anggota organisasi dan penggunaan sumberdaya-sumberdaya organisasi lainnya agar mencapai tujuan organisasi yang telah di tetapkan. Selain itu manjemen oprasional adalah ilmu dan seni mengatur proses pemanfaatan sumberdaya-sumberdaya lainnya secara efektif dan efesien untuk mencapai suatu tujuan tertentu.

\section{Analisis SWOT}

Analisis SWOT merupakan kerangka penganalisisan yang terintegrasi antara internal perusahaan dan lingkungan eksternal, dengan membangun pendekatan SWOT. Analisis SWOT merupakan ringkasan dari keunggulan dan kelemahan perusahaan yang di kaitkan dengan peluang dan ancaman lingkungan. Dengan memikirkan tentang keunggulan dan kelemahan organisasi perusahaan. Diharapkan dapat membantu manajer stratejik untuk melihat organisasinya relative terhadap pesaingnya. Kerangka analisis SWOT mengembangkan wawasan atau pandangan bahwa suatu perusahaan hanya dapat meningkatkan kinerjanya, bila perusahaan ini dapat mengolah pemanfaatan peluang sekaligus 
meminimalisasi

ancaman

lingkungannya.

Analisis SWOT adalah identifikasi berbagai faktor sistematis untuk merumuskan strategi perusahaan (Rangkuti 2014). Analisis ini didasarkan pada logika yang dapat memaksimalkan kekuatan (Strengths) dan peluang (Opportunities), namun secara bersamaan dapat meminimalisasikan kelemahan (Weaknesses) dan ancaman (Threats). Proses pengambilan keputusan strategi selalu selalu berkaitan dengan pengembangan misi, tujuan, strategi, dan kebijakan perusahaan. Dengan demikian perencanaan strategi (strtegi planner) harus menganalisis faktorfaktor strategi perusahaan (kekuatan, kelemahan, peluang, dan ancaman) dalam kondisi yang ada saat ini. Analisis SWOT membandingkan antara faktor eksternal peluang (opportunities) dan ancaman (Threats) dengan faktor internal kekuatan (strengths ) dan kelemahan (weaknesses).

a. Analisis Lingkungan Internal

Analisis lingkungan internal menurut Hunger (2003) para manejer strategi harus dapat mengenali variable-variabel dalam perusahaan yang merupakan kekuatan dan kelemahan yang penting, sebuah variabel merupakan kekuatan apabila menyediakan keunggulan kompetitif. Keunggulan kompetitif adalah sesuatu yang di lakukan perusahaan atau berpotensi untuk dilakukan dengan lebih baik secara relative terhadap percakapan pesaing lain yang sudah ada potensial.

Sebuah variabel merupakan kelemahan apabila berupa sesuatu yang tidak dilakukan dengan baik oleh perusahaan atau perusahaan tidak memiliki kapasitas tersebut. Untuk mengevaluasi pentingnya variabelvariabel tersebut, manajemen harus mengetahui apakah variabel-variabel tersebut merupakan faktor strategis internal, yaitu kekuatan dan kelemahan khusus perusahaan yang akan membantu menentukan masa depan. Menurut Jatmiko (2003).

Berdasarkan pada analisis lingkungan internal pada usaha jasabisnis duplikat kunci ASGAR meliputi:

1). Kekuatan yang ada pada usaha duplikat kunci ASGAR adalah usaha duplikat kunci sudah malang melintang di dunia usaha khususnya usaha di bidang jasa 
duplikat kunci yang mana sudah bisa memprediksi kemana arah tujuan usaha tersebut. Dari segi pencitraan duplikat kunci ASGAR tidak di ragukan lagi karena tidak membutat pelanggan kecewa atas pelayanan yang di berikan oleh pihak jasa duplikat kunci ASGAR. Jasa duplikat kunci ASGAR di dukung oleh pekerja-pekerja yang ramah, handal dan mempunyai tingkat loyalitas yang tinggi terhadap usaha tersebut.

2). Kelemahan yang terjadi pada usaha duplikat kunci ASGAR adalah pada saat musim penghujan dimana hujan tersebut tidak henti-hentinya sehingga membuat jalan selalu basah tergenang air sehingga para pelanggan merasa enggan untuk mencucikan sepeda motornya. Belum lagi pada saat mati lampu yang cukup lama akibat adanya pemasangan atau perbaikan kabel jaringan, karena usaha duplikat kunci sangat tergantung pada supplier listrik. Kadang juga supplier bahan kunci duplikat yang sering terlambat, sehingga stok bahan kunci habis dan persediaan yang di miliki sedikit, otomatis para konsumen pergi dan cari tempat lain.

b. Analisis Lingkungan Eksternal

Menurut Jatmiko (2003), analisis lingkungan eksternal atau biasa di sebut analisis lingkungan peluang dan ancaman organisasi/perusahaan/ kewirausahaan. Disebut demikian karena perubahan lingkungan eksternal perusahaan merupakan sumber utama ancaman dan peluang perusahaan baik di masa sekarang ataupun di masa yang akan datang.

Analisis lingkungan eksternal dilakukan untuk mengukur adanya tingkat peluang dan ancaman yang dapat di manfaatkan oleh usaha duplikat kunci. Analisis lingkungan yang dilakukan pada penelitian ini adalah:

1). Sumber utama ancama yang ada di tempat usaha duplikat kunci ASGAR adalah semakin banyaknya tumbuh usaha-usaha yang sejenis diantaranya pesaing usaha tersebut ialah Duplikat Kunci Reni, duplikat kunci yang berada di belakang superindo.

2). Sumber peluang yang ada di tempat usaha duplikat kunci ASGAR adalah tempat usahanya 
yang sangat strategis yaitu berada di jalan utama yang di lalulalang kendaraan, baik itu pada pagi hari, siang hari, bahkan malam hari. Selain itu usaha duplikat kunci ASGAR berada deakat kampus Universitas Pamulang (UNPAM), Kantor polsek Pamulang dan toko - toko yang beardda di bunderan pamulang.

\section{PENUTUP}

\section{Kesimpulan}

1. Usaha duplikat kunci ASGAR adalah salah satu usaha yang bergerak di bidang jasa, yang beralamat di bunderan pamulang $\mathrm{Jl}$. Siliwangi No. 2, Pamulang, Kec. Pamulang Barat - Kota Tangerang Selatan. Struktur organisasi usaga duplikat kunci ASGAR terdiri dari 1. Pemilik usaha yaitu Ade Suryana, 2. Karyawan keuangan yaitu Rizal, dan 3. Karyawan produksinya yaitu Rozak.

2. Pengelolaan Sumber Daya Manusiannya bapak Ade sangat sederhana contohnya dalam rekrumen karyawannya bapak Ade hanya mengajak anaknya sebagai karyawannya, anak yang peratama namanya Rozak, Rozak sebagai karyawan produksi dan yang kedua namanya Rizal, Rizal sebagai karyawan keuangan. Dalam sistem penggajiannya bapak Ade tiap hari menggajih kepada karyawannya tergantung besar kecil pendapatannya maksimal Rp. 50.000/hari.

3. Pengelolaan Operasionalnya usaha duplikat kunci ASGAR, setiap hari bapak Ade buka dari jam 08:0021:00 WIB, dan usaha tersebut belokasikan di Bunderan Pamulang Jl. Siliwangi No.2, Pamulang, Kec Pamualng Barat - Kota Tangerang Selatan.

4. Pengelolaan pemasarannya

a. Produk yang ditawarkan Usaha Duplikat Kunci yaitu berupa jasa yang menyediakan layanan duplikat kunci dan servis kunci.

b. Harga (Price), Harga yang ditetapkan oleh duplikat kunci ASGAR berda-beda tergantung kuncinya misalkan kunci rumah harga duplikatnya Rp.12.000 - Rp.15.000 sedangkan harga kunci motor 
dan mobil Rp.25.000 Rp.50.000, kemudin harga servis itu tergantung tingkat servisnya sehingga harganya tidak tetap.

c. Distribusi (Place) perusahaan menempatkan usahanya supaya mudah dijangkau oleh konsumen yaitu dengan menempatkannya dekat dengan jalan raya dan dekat kampus universitas pamulang (UNPAM)

d. Promosi (Promotion) Bentuk promosi yang dilakukan oleh usaha duplikat kunci ASGAR selama ini masih promosi dari mulut ke mulut serta testimonial dari konsumen yang telah menggunakan jasa Duplikat Kunci ASGAR

e. Orang (People) merupakan unsur penting dalam pemasaran.Setiap organisasi jasa harus jelas menentukan apa yang diharapkan dari setiap karyawan dalam dengan pelanggan.

f. Bukti fisik (Physical Evidence) bersifat sebuah produk yang berbentuk barang dan Jasa duplikat kunci lebih mengarah kepada kualitas dan kuantitas. g. Proses (Process) yaitu bagaimana caranya membuat proses produksi berupa jasa yang dapat diterima oleh konsumen duplikat kunci ASGAR

h. Pesaing dan Persaingan banyaknya usaha-usaha duplikat kunci dan kunci otomatis yang tidak bisa di duplikat sekarang dapat menjadi ancaman bagi kelanjutan usaha duplikat kunci di masa depan.

\section{DAFTAR PUSTAKA}

Lexy J. Moleong. (2014). Metode Penelitian Kualitatif. Bandung: PT Remaja Rosdakarya

Sugiyono. 2010. Metode Penelitian Pendidikan Pendekatan Kuantitatif, Kualitatif, dan $R \& D$. Bandung: Alfabeta

Sugiyono. 2014. Memahami Penelitian Kualitatif. Bandung: Alfabeta

Sugiyono. 2015. Metode Penelitian Pendidikan Kualitatif. Bandung: Alfabeta.

Nugroho Adi Ilham, Bakar Abu, Fitria Lisye. (2014). Analisis Kelayakan Usaha Pencucian 
Kendaran Bermotor ( Studi Kasus Purwokerto Timur), Jawa Tengah.

Rapini, Titi. Umi Farida. Setyo Adji .2016. Potret Usaha Kecil Dan Menengah Di Kabupaten Ponorogo Pasca Pembinaan. Jurnal Ilmu manajemen. Vol 5 (2).

Wahyuningsih, Sri. 2009. Peranan Ukm Dalam Perekonomian Indonesia. Mediagro. Vol 5 (1).

Nitisusastro, Mulyadi. 2012. Kewirausahaan \& Manajemen Usaha Kecil. Bandung: Alfabeta

Agung setiawan, Indradi. (2010).

Anaalisis Studi Kelayakan

Bisnis Warung Internet. Bogor.

Tri, Dani Danuar. 2013. Pengembangan Usaha Mikro Kecil Dan Menengah (UMKM) Berbasis Ekonomi Kreatif Di Kota
Semarang. Skripsi tidak diterbitkan. Semarang: Fakultas Ekonomika dan Bisnis Universitas Diponegoro Semarang

Tedjasuksmana, Budianto. 2014. Potret UMKM Indonesia Menghadapi Masyarakat Ekonomi Asean 2015. Skripsi tidak diterbitkan. Surabaya: Universitas Katolik Widya Mandala Surabaya

Candra Dwi Prima Diktus Beny,(2014). Pengelolaan dan pengembangan bisnis tempat cuci motor oke di surabaya.program Studi Manajemen, Universitas Kristen Petra Jalan Siliwangi 121-131, Surabaya

Irwanaji, Chaidir.2008. Analisis Bisnis dan Studi Kelayakan Usaha. Fakultas Ekonomika dan Bisnis Universitas Diponegoro Semarang 